\title{
NotAS DE UM PENSAMENTO DA CIRCULAÇÃO E DA TRAVESSIA EM ACHille MBEMBE ${ }^{1}$
}

\author{
Alex Sander da Silva ${ }^{2}$ \\ Christian Muleka Mwewa ${ }^{3}$
}

Resumo: Neste ensaio, pretende-se uma aproximação crítica e interpretativa sobre o conceito de "devir negro", na atualidade, trazido, sobretudo, pelo pensador camaronês Achille Mbembe. Seu pensamento se insere num contexto de fluidez da compreensão desses temas, a partir da lógica capitalista, no continente africano e no mundo. Dessa maneira, buscou-se refletir acerca da constituiçáo do pensamento de Mbembe e da forma como ele compreendeu as práticas de governamentabilidade, na superação da dominaçấo colonial. Defende-se que é preciso afirmar-se negro, para negar o lugar que lhe foi imputado, ou seja, empreender um processo de negação para um "devir". Portanto, negar-se como "o outro" do "outro", mas, sim, afirmar-se como seu igual na diferença. Com efeito, a estereotipia negativa contra o negro e o aprofundamento das diferenças entre os grupos étnicos ganham novas e outras dimensôes, em função do modo de exploração capitalista.

Palavras-chave: Achille Mbembe. Circulação. Travessia. "Devir negro”.

\footnotetext{
${ }^{1}$ Texto produzido com auxílio financeiro de pesquisa pró-stricto da FUCRI, fomento da FAPESC e do CNPq.

2 Professor do Programa de Pós-Graduação em Educação da Universidade do Extremo Sul Catarinense (UNESC), Criciúma, SC-Brasil. (D) https://orcid.org/0000-0002-0945-9075, E-mail: alexsanders@ unesc.net.

${ }^{3}$ Professor e coordenador do Programa de Pós-Graduação em Educação (Campus Três Lagoas/CPTL) e do Programa de Pós-Graduação em Educação (Campus Campo Grande), ambos na Universidade Federal de Mato Grosso do Sul (UFMS), Campo Grande, MS - Brasil. (iD https://orcid.org/00000002-7079-5836. E-mail: christian.mwewa@ufms.br.
}

https://doi.org/10.1590/0101-3173.2022.v45esp.03.p33 


\section{INTRODUÇÃo}

A emergência do pensamento circular e da travessia, em Achille Mbembe, se configura no pano de fundo deste ensaio. A "descoberta" do pensamento de Achille Mbembe se dá, sobretudo, pelo crescimento dos chamados estudos "pós-coloniais", "descoloniais" ou, como alguns preferem chamar, "decoloniais". Nosso objetivo, aqui, não é discutir essa terminologia, mas pensar a potência criativa e ressignificada advinda do continente africano, a partir de Achille Mbembe. Esse objetivo é alcançado, pela reflexão sobre a constituiçáo do pensamento de Mbembe e do modo como ele compreendeu as práticas de governamentabilidade, na superação da dominação colonial. Nisso consiste uma dobra no pensamento "habituado", habitado e predominantemente centrado no continente europeu e/ou norte-americano.

Voltar o olhar e a atenção ao continente africano implica alguns movimentos, como reconhecer que não há uma homogeneidade no pensamento, no continente. Há, sim, que se situar esse pensamento no seu contexto histórico e em qual movimento se está procurando. No caso de Mbembe, trata-se de um pensamento caracterizado por uma “[...] autocrítica e pela busca de referenciais endógenos nas ciências sociais e na filosofia para a interpretação dos fenômenos observados a partir do próprio continente." (MACEDO, 2016, p. 313). Porém, não podemos nos esquecer de que a formação de Mbembe se deu no continente europeu. Isso justifica a operação dialética presente no seu pensamento, a qual se diferencia da forma de apreensáo da realidade, a partir dos contextos africanos com seus modos próprios de ler o mundo. No caso de Mbembe, essa leitura articula tal dialética, por meio dos elementos contextuais de África "negra". Aí reside a potência crítica desse autor, ou seja, ele realiza uma crítica imanente sobre a lógica do processo subalternizante da colonização.

Outro aspecto de destaque do pensamento africano diz respeito ao aumento significativo da "[...] institucionalidade acadêmica, do número de intelectuais de diferentes disciplinas, formaçóes teóricas, políticas e ideológicas, formados parcialmente nos centros de poder intelectual do hemisfério Norte e parcialmente na África.” (MACEDO, 2016, p. 314). Por outro lado, isso não significa afirmar que esses intelectuais não existiam, mas apenas passaram a ser percebidos diante da saturação do pensamento único. As contribuiçóes teóricas e metodológicas dos pensadores africanos, particularmente, daquilo que conhecemos como filosofia e das ciências sociais, têm colocado as discussóes sobre o pós-colonialismo num outro 
patamar, a começar pela discussão de atrelar o seu pensamento sempre a um passado que não os glorifica, a saber, o colonialismo.

Portanto, referir-se ao atual pensamento dos intelectuais oriundos do continente africano com uma terminologia que retoma o passado nefasto diz muito sobre a inserção desses intelectuais no contexto científico do ocidente. Os prefixos "pós-"; "des-" ou "de-", quando acompanhados do vocábulo “-colonial”, reafirmam a marginalidade dos intelectuais, frutos da brutalidade sanguinária do Ocidente. O iluminismo, por exemplo, não é atrelado às violências que assolaram o continente europeu, antes do surgimento dessa corrente de pensamento.

Neste artigo/ensaio, pretende-se uma aproximação crítica e interpretativa da perspectiva pós-colonial, sobre o conceito de "devir negro", na atualidade, trazido, sobretudo, pelo pensador camaronês Achille Mbembe. Sabe-se que a ideia do "devir" está ancorada no projeto monumental de Gilles Deleuze e Félix Guattari, qual seja, "capitalismo e esquizofrenia”. Portanto, o "devir negro" flerta com o "devir máquina”. A proposta busca revisitar a obra Crítica da Razão Negra (2017), de Mbembe, considerado um dos pensadores mais profícuos e ativos sobre história e política africanas da atualidade. Mbembe é autor de outras obras de impacto, no que se refere à questão negra, como, por exemplo, De la postcolonie (2000) e Sortir de la grande nuit (2010). Mas, por ora, fixamos o nosso modelo argumentativo também na Crítica da Razão Negra (2017).

Primeiramente, fazemos algumas observaçōes sobre a obra "Crítica da Razão Negra", sobretudo tratamos sobre o nome "negro" atribuído aos genes de origem africana da era colonial, especialmente, em função da ideia do "devir-negro do mundo", apontada por Mbembe (2017). Em seguida, refletiremos sobre a questão da governamentabilidade decolonial, a partir da metáfora do "sair da grande noite" e abordaremos o significado desse sair, relacionando-o com a questão do significado do pensamento da circulação e da travessia em Mbembe (2001, 2013a, 2013b, 2015). Por fim, espera-se, com este ensaio, provocar o debate para a necessidade de reconhecimento, com base no pensamento de Achille Mbembe, de problematizar as interconexóes da dominação colonial pós-libertação, no contexto de fluidez da compreensão desses espaços, a partir da lógica capitalista. 


\section{O DEVIR-NEGRO DO MUNDO PODE SER UM CAMINHO SEM VOLTA?}

Quisemos escrever este livro à semelhança de um rio com múltiplos afluentes, neste preciso momento em que a

história e as coisas se voltam para nós, e em que a Europa deixou de ser o centro da gravidade do mundo.

(MBEMBE, 2017, p. 9).

Em seu livro Crítica da Razão Negra, o pensador Achille Mbembe faz, na introdução da obra, um prenúncio do que ele chama de o "grande acontecimento", ou a "experiência fundamental da nossa época", isto é, afirma que a Europa já não é mais o "centro do mundo". Desse modo, abriramse novas possibilidades, e novos olhares estão voltados para o continente africano, na qual é possível repensar a história da humanidade. No entanto, existem dois caminhos, no seu entendimento: por um lado, "pode suscitar perplexidade" ou, por outro lado, "[...] fazer-nos mergulhar num tormento ainda maior" (MBEMBE, 2017, p. 9). Portanto, o deslocamento gravitacional não significa, necessariamente, assumir um outro centro (outro do mesmo), mas um processo de configuração de uma outra lógica para apreensão da realidade. Ou seja, instaura-se uma revolução na ciência normal, como nos ensinou Thomas Kuhn.

Mbembe, nessa introdução, abre caminhos para o pensar crítico sobre o ser negro, ou aquilo que ele chama de "o devir-negro do mundo". Para o autor, a definição do negro está intimamente associada ao sistema político colonial, uma espécie de nascedouro de um personagem necessário para o funcionamento desse sistema. Um personagem com características próprias para o domínio e espoliação, uma condição de subalternizado para exploração do colonialismo. Em uma palavra: uma invenção que se configura num processo esquizofrênico, no qual o paciente (a Europa/Ocidente) acredita na doença (negro) que ele mesmo inventou.

Mbembe (2017) faz uma reconstrução conceitual do ser negro, em seu movimento de duplo sentido. Uma espécie de ontologia reversa ou paradoxal, a qual coloca, de um lado, o negro como um não-ser, um nome vinculado às expressões espúrias da condição humana inventadas pelo ocidente. Por outro lado, apresenta-o como um significado universal, "[...] como signo luminoso da possibilidade de redenção do mundo e da vida num dia de transfiguração." (MBEMBE, 2017 p. 19). 
Com sua obra, Mbembe busca fazer uma espécie de deslocamento da imagem do ser negro de "[...] uma realidade heteróclita, múltipla e fragmentada" (MBEMBE, 2017 p. 19), para uma imagem universal da condição de nós todos nesse momento de crise global. Clara está a dimensão metafórica da palavra "negro", em alusão ao processo colonial empreendido pelos europeus, no continente negro. Afinal, a que isso corresponde? Isso indica que a condição de toda a humanidade submetida aos ditames da era capitalista neoliberal se tornaria a negra, colocada numa espécie de "devirnegro do mundo." (MBEMBE, 2017, p. 21), ou seja, a escória da humanidade a ser espoliada. Deixaria de ser uma mera passagem superável da civilização na construção da igualdade, para se tornar uma forma possivelmente aceitável de lidar com as diferenças e no reconhecimento do outro, que se tornaria seu igual. Na justificativa da sua obra, Mbembe (2017, p. 21-22) assinala:

Ao privilegiar uma forma de reminiscência, meio solar e meio lunar, meio diurna e meio noturna, tínhamos em mente uma única questão - como pensar a diferença e a vida, o semelhante e o dissemelhante, o excelente e o em comum? A experiência negra resume bem tal interrogaçáo, preservando na consciência contemporânea o lugar de um limite fugaz, de uma espécie de espelho móvel [não narcísica].

A essa ideia central no pensamento de Mbembe está subjacente uma outra: o significado do declínio da Europa no mundo e a consequente deslocação do centro de gravidade do mundo para fora dela. Mas a força centrífuga ainda está em movimento. Será que, nesse sentido, quando o autor fala do negro como "devir", estão no seu horizonte os processos de "de(s) colonização" política, econômica e cultural da África e do resto do mundo? É possível pensar que a libertação dos grilhóes da escravização e das lutas anticoloniais ainda não aconteceram, de forma total, justamente porque ainda nos deparamos com constantes situaçóes constrangedoras e humilhantes, as quais ainda insistem em acontecer para as pessoas negras, dentre outras consideradas desviantes múltiplos, não apenas do continente africano?

Ao povo "negro" é imputado o carma. O povo negro carrega a marca da escravidão em seu próprio corpo (como se os chamados brancos nunca tivessem sido escravizados), no constante apelo à produção da sua autonegação produzida. Para Mbembe, o negro não existe por si só: ele é produzido como necessidade de dominação, isto é, "[...] produzir o negro é produzir um vínculo social de submissão e um corpo de exploração.” (MBEMBE, 2017, 
p. 40, grifo do autor). Portanto, o "negro" passa a ser o outro, ao qual nego a substancialidade da existência em afirmação da minha. Diferente de não o considerar como recíproco. Diante dessa observação, pode-se dizer que a luta por reconhecimento dos negros está um passo atrás das lutas do feminismo beauvoiriano. Ou seja, primeiro o negro precisa existir para requerer uma reciprocidade com o homem branco. Nessa tendência, teríamos de lidar com uma perspectiva da questão negra relacionada com a "raça". Em termos biológicos, o conceito de "raça" náo faz sentido, mas isso não impediu que a Europa inventasse as "raças", escolhendo qualquer traço que fosse conveniente, como a cor da pele, por exemplo, para classificar os grupos sociais diversos do europeu e se colocar no topo da pirâmide racial (MUNANGA, 2005-2006).

Ao ser usado com conotação política, o conceito de raça permite aos negros, por exemplo, valorizar a característica que os difere das outras populaçóes e romper com as teorias raciais formuladas no século XIX e que, até hoje, permeiam o imaginário popular. Portanto, é preciso afirmarse negro para negar o lugar que lhe foi imputado, ou seja, empreender um processo de negação para um "devir". Logo, negar-se como "o outro" do "outro", afirmando-se como seu igual na diferença. O termo "raça”, usado nesse contexto, tem uma conotação política e é utilizado com frequência nas relaçóes sociais brasileiras, para informar como certas características físicas, como cor da pele, tipo de cabelo, dentre outras, influenciam, interferem e até mesmo determinam o destino e o lugar social dos sujeitos, no interior da sociedade brasileira.

Desse modo, o devir-negro do mundo está vinculado à chamada "razão negra”, veiculando um propósito diferente para a apreensão da realidade. De acordo com Mbembe (2017, p. 57), essa corresponde a um conjunto de “[...] vozes, enunciados e discursos, saberes, comentários e disparates, cujo objeto é a coisa ou as pessoas 'de origem africana' e aquilo que afirmamos ser o seu nome e sua verdade." A razão negra consiste num conjunto "de discursos como de práticas" que busca conduzir um entendimento do ser negro "[...] enquanto sujeito de raça e exterioridade selvagem, passível de desqualificação moral e de instrumentalização prática." (MBEMBE, 2017, p. 58). Assim, o estágio atual do neoliberalismo nos iguala a todos numa épica razão negra, sendo o "devir" não mais uma potência, mas, sim, um ato.

Nesses termos, é importante tratar a questão da razão negra dentro da complexidade do racismo, no qual muitos são igualados para serem excluídos. Mesmo as posturas que têm acordo de que "raça" enquanto conceito biológico 
não existe ainda não têm consenso no trato com o racismo institucionalizado. Nesse sentindo, pode-se falar no racismo social, o qual promove restriçóes de acesso aos bens produzidos socialmente pela humanidade. Nesse caso, esse racismo se torna estrutural, por perdurar há muito tempo e regimentar a forma como nos relacionamos uns com os outros, em diferentes contextos sociais. Nesse sentido, pode-se dizer que "[...] la dimension diabolique du discours ethnographique marque aussi le retour du trope satanique qui sétait diffusé partout lors des engagements coloniaux européens tout au long de l'histoire du XIXe siècle." (STEINMETZ, 2004, p. 50).

Nossa herança escravocrata persiste táo enraizada nos costumes e práticas cotidianas que convém denunciá-la; especialmente, nos locais em que ela se apresenta sem anúncio, é preciso dizer o nome, ou seja, nomeá-la como denúncia e contra qualquer tipo de silenciamento conivente. O raciocínio racista, quando formulado de forma cordial, com sorrisos simpáticos, tornase particularmente perigoso, pois domestica a rebeldia, amansa a indignação e enraíza ainda mais essa mentalidade no espírito coletivo. No entender de Mbembe (2017, p. 66),

[...] o racismo consiste, antes de tudo, em converter em algo diferente, uma realidade diferente. Além de uma força de desvio do real e que fixa afectos, é também uma forma de distúrbio psíquico, e é por isso que o seu conteúdo reprimido vem brutalmente a superfície. Para o racista, ver um negro é não ver que ele não está lá; que ele não existe; que ele mais não é do que o ponto de fixação patológico de uma ausência de relação. É, portanto, necessário considerar a raça enquanto um aquém e um além do ser. É uma operação do imaginário, o lugar onde se encontram as regióes obscuras e sombrias do inconsciente.

A razão negra está condicionada a uma humanidade castrada, cuja condição destinada é o da subalternidade. No contexto neoliberal, negro refere-se a todos os que náo possuem os meios de produção, configurando-se apenas em trabalhadores desprovidos da consciência de si. Mas, amargurados na ilusão ideológica de produzir-se a si mesmos, não mais para vender sua força de trabalho, todavia, como meios/instrumentos de produçáo, assim como os negros de outrora. A subjetividade negra esbarra no dado ostensivo e objetivado da corporeidade, cuja avaliação, no entanto, ainda é preconceituosa. Podemos

4 "[...] a dimensão diabólica do discurso etnográfico também marca o retorno do tropo satânico que se espalhou por toda parte, durante os combates coloniais europeus, ao longo da história do século XIX" (tradução nossa). 
sustentar que a cidadania racial, geralmente mutilada, é emblemática, quando se assume ser negro. Os interesses cristalizados, os quais produziram convicçóes escravocratas arraigadas, mantêm os estereótipos, que não ficam no limite do simbólico, pois incidem sobre os demais aspectos das relaçóes sociais para além da cor da pele. Na esfera pública, o corpo acaba por ter um peso maior do que o espírito, na formação da identidade racial afirmativa.

No segundo capítulo da Crítica da Razão Negra, intitulado "O poço da alucinação", Mbembe afirma que o termo "negro" tem origem europeia e aparece pela primeira vez escrito num texto em Língua Francesa, no início do século XVI, mas apenas no século XVIII, auge do tráfico de escravos, seu uso se torna corrente (MBEMBE, 2017, p. 76). O termo está intimamente vinculado a "[...] uma ganga de disparates e de alucinaçóes que o ocidente (e outras partes do mundo) urdiu, e com a qual revestiu pessoas de origem africana muito antes de serem capturadas nas redes do capitalismo emergente dos séculos XV e XVI.” (MBEMBE, 2017, p. 76).

Conforme Mbembe (2017), o negro está correlacionado com África, uma "relação de coprodução" dos dois conceitos (o de negro e o de África). Ser negro e África (africano?) está absolutamente imbricado na tessitura das elaborações racistas orquestradas pelo Ocidente. É na conjunção desses dois termos que reside o germe estruturador do racismo. Assim, os brancos sulafricanos também são de África. O "também” faz toda a diferença na afirmação de "ser africano", pois outros já o são por imputação. É com a chegada do europeu ao continente africano que o conceito toma forma, num revestimento externo disseminado para ser inculcada essa enorme "ganga de disparate", cuja função era criar uma "ferida viva que rumina", que produz o ser do outro em sua negação de si.

Para ilustrar essa situação, Mbembe menciona os autores Franzt Fanon, em Peau noire, masques blancs ${ }^{5}$, que aborda as feridas e as possibilidades de cura; e James Baldwin, que trata das feridas como um veneno, sendo necessário notar o que ele provoca na pessoa que o fabrica e o destila e na pessoa a quem é ministrado (MBEMBE, 2017). Se é no veneno que pode existir o antídoto, faz-se necessário um giro dialético na assunção do ato de ser negro, uma vez que não é mais possível inverter essa terminologia. O "devir" passa a ser o locus privilegiado das possibilidades do novo.

${ }_{5}$ Pele Negra, Máscaras Brancas. 
Evidente está que essa perspectiva tensiona o "devir negro" em Mbembe. Se é somente por meio do pensamento que podemos avançar na compreensão e apreensão do mundo, então, faz sentido fazer o caminho de volta do "devir", a partir do próprio Mbembe, ou seja, parar a saga para o futuro e perceber o presente como palpável e mutável. O negro já é negro dito por outros, mas os outros estáo se tornando negros, num mundo objetivador das potencialidades subjetivas. Ora, os negros podem tomar a vanguarda em dizer a esse mundo como ser negro enquanto ato e não potência. Mas essa é uma aposta sem garantias. Por isso, vale a pena.

$\mathrm{Na}$ trilha de Fanon, supracitado, Mbembe afirmaria que vincular o "ser negro" a "mentiras" e "alucinações" toma conta das consciências das próprias pessoas negras, como um "[...] invólucro exterior cuja função foi, desde logo, substituir-se ao seu ser, vida, trabalho e linguagem." (MBEMBE, 2017 , p. 77). Nesse sentido, a imagem do corpo negro que se constituiu ao longo dos tempos por estereótipos, atualmente, se expressa como formas de violência, as quais têm um único resultado: a desumanização ou morte dos indivíduos negros. Para Roger Bastide (1973), “[...] a apologia à força física do negro, subentende a ideia de que ele só serve para trabalhos forçados, como a apologia sexual subentende uma opinião pejorativa de sua moralidade." $\mathrm{Na}$ mesma direção, o autor ainda afirma:

L'attribution d'un caractère satanique à la prose coloniale fait écho à un argument aparu dans les récentes études sur le colonialisme, qui veut que ce dernier soit un produit, presque direct, du discours orientaliste, ethnographique ou racial. ${ }^{6}$ (STEINMETZ, 2004, p. 49).

O corpo negro é marcado por esses estereótipos, a fim de designar a condição de subserviência que lhe é requerida. Nessa perspectiva, é interessante notar uma censura psicológica e simbólica, para compreender uma corporeidade negada. Nessas condições, seu corpo é uma não presença para o outro, uma negação de sua subjetividade humanizada, de modo que sua identidade, seja ela corporal, seja psicológica, é uma conquista demorada e sofrida, formada de heranças e aquisiçóes culturais, de atitudes aprendidas e inventadas e de formas de agir e de reagir:

\footnotetext{
6 "A atribuição de um caráter satânico à prosa colonial ecoa um argumento, que surgiu em estudos recentes sobre o colonialismo, de que este é um produto quase direto do discurso orientalista, etnográfico ou racial." (TN).
} 


\begin{abstract}
"Negro" é, antes de mais, uma palavra. Uma palavra remete sempre para qualquer coisa. Mas a palavra tem também uma espessura e densidade próprias. Uma palavra existe para evocar alguma coisa na consciência daquele a quem é endereçada ou que a ouve. Quanto mais densidade e espessura tem, mais a palavra provoca uma sensaçáo, um sentimento e até um ressentimento a quem se destina. Existem palavras que magoam. A capacidade de as palavras ferirem faz parte do seu próprio peso. "Negro" é suposto ser, e sobretudo isso, um nome. Aparentemente, cada nome carrega um destino, uma condição mais ou menos genérica. "Negro" é, portanto, o nome que me foi dado por alguém. Não o escolhi originariamente, herdo este nome pela posição que ocupo no mundo. Aquele que está marcado com o nome "Negro" náo se deixa enganar por esta proveniência externa. (MBEMBE, 2017, p. 255-256).
\end{abstract}

E quando se remete à ideia de um "devir-negro" do mundo, num primeiro momento, causa estranhamento e espanto, contudo, em Mbembe, a questão do negro "[...] está ligada à história do capitalismo." (MBEMBE, 2017, p. 299). Para ele, o capitalismo tem um "duplo instinto": de um lado, o "[...] da violaçáo ilimitada de todas as formas de interdito e, por outro, "[...] da abolição de qualquer distinção entre os meios e os fins." (MBEMBE, 2017, p. 299). E o negro está como produto desse duplo instinto e do que Mbembe (2017, p. 299) chama de "[...] a figura exemplar de uma violência sem limites e de uma precariedade sem limites." Com efeito, no capitalismo, todos os que não são donos dos meios de produçãao são negros, isto é, subalternizados.

O capitalismo avançava rapidamente com seu poder predador para explorar os mais recônditos sítios do Planeta. E, na visão de Mbembe (2017, p. 299, grifo do autor), precisou de "[...] subsidios raciais para explorar os recursos do Planeta." A ideologia racista e a exploração capitalista consolidamse, assim, num único e mesmo processo, essencial para a formaçáo do próprio capitalismo. E isso é tão presente que o próprio capitalismo não hesita de "[...] colonizar o seu próprio centro, e que as perspectivas de um devir-negro do mundo nunca tenham sido táo evidentes." (MBEMBE, 2017, p. 299, grifo do autor). Por conseguinte, assumir-se negro é antever o fim último patente a muitos, no sistema capitalista objetificador do governo interno e externo dos seres humanos. 


\section{GOVERNAMENTALIDADE DESCOLONIZADA OU DE COMO SAIR DA GRANDE NOITE}

Por que o ser humano investe contra os próprios interesses? Podemos assegurar que o pensamento de Achille Mbembe se constitui como uma análise crítica da própria condiçáo da vida social do continente africano, no período pós-colonial, sobretudo, azeitado pelo capitalismo avançado ou aquilo que podemos chamar de sua versão neoliberal. Essa análise se dá, sobretudo, desde o início de sua trajetória profissional, em Camaróes, passando pelos seus estudos na França e nos Estados Unidos.

Em seu ensaio "On the post colony" (Sobre a pós-colônia), busca analisar a experiência profunda das sociedades africanas que viveram em regimes coloniais de dominação marcados pela extrema violência exercida, nesse período, por esse sistema. De acordo com Mbembe (2001, p. 25), a "póscolônia” seria uma espécie de "poder bruto" que impregna um determinado controle sobre os sujeitos "herdeiros" do sistema colonial. Seria também um conjunto de signos "[...] partilhado por aqueles que detém o monopólio sobre a vida e a morte, e o sistema de signos quais esse poder se imagina." (MACEDO, 2016, p. 328):

Une analyse du champ du pouvoir colonial permet d'expliquer pourquoi le discours ethnographique est habituellement plurivoque, au contraire de l'image monolithique donnée par de nombreuses aplications de la théorie du discours colonial. [...] La compétition dans le champ du colonialisme d'outre-mer sorganisait autour d'enjeux spécifiques et de formes particulières de capitaux. Les colonisateurs attendaient les uns des autres quils reconnaissent mutuellement leur suposée sagacité ethnographique, cette capacité à capturer les caractères et la subjectivité des colonisés. ${ }^{7}$ (STEINMETZ, 2004, p. 51-52).

Em geral, quando Mbembe (2001) se refere ao colonialismo, tem em vista as consequências para os colonizados e as distintas formas de violência a que foram submetidos. Entretanto, há um fato que não passa despercebido por Mbembe e que tem a ver com a desestruturação das comunidades, ou da chamada unidade nacional, quando seus membros, ou pelo menos grande parte deles, são convencidos, aliciados ideologicamente pela colônia. Por outro

\footnotetext{
7 "Uma análise do campo do poder colonial ajuda a explicar por que o discurso etnográfico é geralmente multívoco, ao contrário da imagem monolítica dada por muitas aplicaçôes da teoria do discurso colonial. [...] A competição no campo do colonialismo ultramarino foi organizada em torno de questôes específicas e formas particulares de capital. Os colonizadores esperavam, uns dos outros, que reconhecessem mutuamente sua suposta sagacidade etnográfica, essa capacidade de capturar os personagens e a subjetividade do colonizado." (TN).
} 
lado, atualmente, esse processo de aliciamento pode indicar uma dubiedade na ação, uma vez que a inocência dos chamados africanos deixou de ser presumida, ao menos para eles. A partir de África, é possível afirmar que a escravização nunca foi um produto importado, pois, apesar das diferenças nos princípios e meios, o fim era o mesmo, ou seja, a subserviência do outro: uma na aculturação (em África) e outra na exploração e espoliação da sua força de trabalho (nas Américas).

Para Mbembe, o pós-colonialismo seria uma espécie de arena de disputas e o seu estudo "[...] assenta, então, no exame das formas de sujeição e das formas de indisciplina que eventualmente possam conduzir a emancipação dos sujeitos." (MACEDO, 2016, p. 328). Dessa feita, Mbembe busca renovar as "forças" da luta anticolonial no campo epistêmico, tal como fizeram inúmeros intelectuais africanos, particularmente em meados do século XX, haja vista que a emancipação subjetiva se dá no embate tanto subjetivo quanto objetivo.

Em sua obra Sortir de la grand nuit (2013b) (Sair da grande noite), Mbembe apresenta esse embate subjetivo, através de um programa epistêmico revitalizado para o processo e os desafios da descolonização. Nesse ensaio, Mbembe busca mesclar uma narrativa autobiográfica do seu testemunho dos anos de infância, em Camarôes, em que articula dois movimentos que dáo a tônica do livro, que são a metáfora e a literalidade dos temas, respectivamente, da "noite e da morte".

O primeiro capítulo, intitulado "A partir do crânio de um morto. Trajectórias de uma vida” (p. 31-48), o próprio autor considera como sendo “[...] um registo deliberadamente narrativo e autobiográfico" (MBEMBE, 2014, p. 15) que dá o direcionamento da obra. Sua memória ativa de quando era criança recorda "[...] os cadáveres ao relento, revolvidos por escavadeiras; relembra também os revolucionários tornados terroristas pelo discurso do poder colonial, mortos aos quais foi negado o reconhecimento de uma sepultura." (MIGLIAVACCA, 2014, p. 560). Tal tragédia já foi muito bem retratada outrora por Sófocles, em Antígona, quando a esse é negada, pelo soberano, a possibilidade de sepultar a pessoa que amava:

[...] escuridão da noite - máscara opaca e, no entanto, tão penetrável - me imbuía, todas as vezes, de um medo indescritível com a sua legião de pirilampos sobre os quais se dizia repetidamente que, em cada um, germinava um fantasma, com os seus cânticos lúgubres de sabor enferrujado, salgados das corrupçóes da feitiçaria, essa espécie de lapidação, 
de exaurimento perverso e desmesurado, que resisitia aos destroços do dia e às eras do mundo, com o crânio das cavernas. (MBEMBE, 2014, p. 33).

As agudas contradiçóes sociais existentes hoje, no continente africano (não apenas lá), têm caracterizado as condiçôes subumanas de existência de parcela grande da população. O teor político da obra identifica a contradição entre a metrópole e a colônia, especialmente incrustada nas orientaçóes políticas e sociais do peso do racismo. Isso é observado por Mbembe (2014), quando destaca a situação das pessoas, no continente, mesmo no pós-colonialismo, as quais ainda vivem no limite das condiçóes de sobrevivência, marcadas por profundas desigualdades sociais, sem que tenham poder livre de decisão de escolha política:

$\mathrm{Na}$ verdade, é um turbilhão destruidor, imponderado ou brusco, no meio de tantos desastres - ao qual crescem apoquentaçóes inúteis, a improvisação crônica, a indisciplina, a dispersão, o desperdício e um peso de indignidade, desprezo e humilhação ainda mais persistentes do que na época colonial. $\mathrm{Na}$ maioria dos casos, os africanos náo dispóem sequer da possibilidade de eleger livremente os seus dirigentes. (MBEMBE, 2014, p. 23).

Além disso, não há como discutir a questão das desigualdades sociais, em África, sem levar em consideração as condiçôes a que a população negra foi submetida, durante o período colonial e as lutas por libertaçóes nacionais. Os grilhóes do colonialismo deixaram profundas marcas no continente, no entanto, o debate sobre os processos de libertação não se deu de modo unívoco, nas formas de transferência de poder. Mbembe (2014, p. 49) escreve:

[...] essa transferência de poder é geralmente o fruto de negociações pacíficas e compromissos assumidos entre as elites políticas dos novos países independentes e as antigas potências coloniais, ou uma consequência de uma luta armada para abolir a ascendência estrangeira, resultando na derrota, ou mesmo na evicção dos colonos e na reapropriaçáo do território nacional pelo novo poder autóctone.

Aqui, podemos enfatizar a preocupação de Mbembe com os pactos da descolonização, em uma expressão: lutas pelas independências. Certamente, um grande desafio para Mbembe foi buscar entender de que maneira o colonialismo ainda opera, a fim de empreender formas de combatê-lo. Mas, 
diante da impossibilidade do combate, procurou como compreendê-lo na sua imanência. Desse modo, o pensador camaronês inaugura um modo de se contrapor ao colonialismo com as forças do próprio continente. Para ele, isso será possível com a apropriação conceitual sobre a própria colonização, concebida como "[...] uma plena categoria política, polêmica e cultural." (MBEMBE, 2014, p. 49).

Como participante de uma nova geração de intelectuais, Mbembe apresenta uma forma original de tratar do tema da descolonialidade. $\mathrm{Na}$ sua consideração, a África constitui um continente caracterizado por uma intensa "[...] circulação de pessoas, processos de dispersão e imersão, crioulização e mestiçagem, pela alta capacidade de adaptação e recomposiçâo [dialética].” (MACEDO, 2016, p. 333). A circularidade, como princípio do continente africano, estrutura os processos de travessia, ou seja, de superação:

Desde a sua eclosão, esse pensamento foi objecto de interpretações muito diversas e suscitou, em intervalos relativamente frequentes, vagas polémicas e controversas - que aliás persistem — e mesmo contestaçóes totalmente contraditórias entre si. Também engendrou práticas intelectuais, políticas e estéticas tão profusas quanto divergentes, a ponto de, por vezes, se questionar acerca dos elementos constitutivos da unidade. Não obstante essa fragmentação, pode afirmar-se que, no seu núcleo central, a crítica pós-colonial visa aquilo que poderia designar-se pela interpolação das histórias e a concatenação dos mundos. Dado que a escravatura, e sobretudo a colonização (mas também as migraçôes, a circulação das formas e dos imaginários, dos bens, das ideias e das pessoas) desempenhou um papel decisivo nesse processo de colisão e de imbricação dos povos, não é surpreendente que as tenha convertido nos objectos privilegiados dos seus estudos. (MBEMBE, 2014, p. 101-102).

Para isso, Mbembe classificou aquilo que denominou Afropolitanismo como uma aposta sobre uma nova visão do continente e sobre ele, uma abertura das sociedades africanas para uma nova forma de se mostrar ao mundo. A tentativa diz respeito a pensar as interconexôes da dominação colonial póslibertação em contexto de fluidez da compreensão desses espaços, com base na lógica capitalista a ser confrontada.

Nessa perspectiva, Mbembe quer refletir a propósito da constituição dos sujeitos africanos e do continente, em novos modos nas práticas de governamentabilidade, compreendidas para superação da dominação colonial. A governamentabilidade precisa ter dois nascedouros como 
princípio, quais sejam: (1) o processo de constituição e emancipação subjetiva; e (2) a contraposição à realidade objetiva, isto é, enquanto permanecer a realidade tal qual a emancipação se torna um permanente telos da não identidade. A aposta seria para um novo olhar sobre o continente e seu futuro como uma marca característica própria do africanismo. Esse novo olhar deve ser subjetivo e objetivo, ou seja, interno dos próprios africanos na percepção daquilo que é externo aos próprios africanos, no permanente embate - uma aposta para sair da "grande noite" da modernidade colonial que domina o continente, por décadas.

Em seu artigo "Afropolitanismo" (2015), Mbembe indica que "[...] o centro por excelência do afropolitanismo é, nos dias de hoje, Johanesburgo, na África do Sul.” A capital da África do Sul, uma metrópole “[...] forjada no ferro de uma história brutal, uma figura inédita da modernidade africana está se desenvolvendo (MBEMBE, 2015, p. 71). Esse termo veio substituir o que se constituiu como o pan-africanismo e o chamado discurso da négritude $e^{9}$ que, por fim, veio a identificar a mesma brutalidade empreendida ao continente.

O afropolitanismo se coloca em função dos problemas atuais do continente, numa imbricação entre o que é local e o que é de fora. Mais precisamente, entre o que seria autenticamente africano e aquilo que vem da experiência externa. Essa capacidade de reconhecimento, daquilo que Mbembe (2014, p. 184) chamou de uma

[...] relativizaçáo das raízes e dos pertencimentos primários e essa maneira de abraçar em todo conhecimento de causa o que lhe é estranho, estrangeiro e de longe, essa capacidade de reconhecer sua face no rosto do estrangeiro e de valorizar os traços do distante no próximo, de domesticar o náo familiar, de trabalhar com coisas o que tem todo o jeito de serem contrárias - é esta sensibilidade cultural, histórica e estética que o termo "afropolitanismo" bem indica.

Esse termo caracteriza aquilo que podemos identificar, em Mbembe, como um pensamento em circulaçáo e de travessia. Portanto, o circular configura-se como um ponto de fuga para uma travessia segura. Se é nos antepassados que reside a história, é preciso circular para contar a versão dos

\footnotetext{
8 Texto publicado na Áskesis, v. 4, n. 2, p. 68-71, jul./dez. 2015, com tradução de Cleber Daniel Lambert da Silva.

${ }^{9}$ Importante conferir o texto "Negritude, construção e contestação do pensamento político-intelectual de Léopold Sédar Senghor (1928-1961)", de Gustavo de Andrade Durão. In: MACEDO, José Rivair (org.). O pensamento africano no século XX. São Paulo: Outras Expressōes, 2016. p. 23-52.
} 
vencidos que jaz no hades. Esse seria, em seu entendimento, o potencial do continente africano. Não apenas como um lugar geográfico em sua diversidade, porém, como potência epistêmica que pode correr "[...] o risco de influenciar singularmente sobre a vida cultural e a criatividade estética e política dos próximos anos." (MBEMBE, 2015, p. 68). É importante perceber que esse procedimento de inversão pode indicar certa equidade nas relaçôes, a qual, por fim, pouco esclarece, quando não está assentada na proteção da vida humana.

\section{ConsideraÇóes FinaIs}

A tentativa, aqui, foi de pensar as interconexôes da dominação colonial e a compreensão dessa dominação na pós-libertação, no pensamento de Achille Mbembe. Seu pensamento se insere num contexto de fluidez da compreensão desses temas, a partir da lógica capitalista, no continente africano e no mundo. Assim, buscou-se refletir acerca da constituição do pensamento de Mbembe e da maneira como ele compreendeu as práticas de governamentabilidade, na superação da dominação colonial ainda persistente.

A proposta de Mbembe diz respeito a se aproximar dos nossos atuais problemas civilizatórios e de sua interferência direta ou indiretamente nas orientaçóes teóricas e práticas, à luz de um olhar descentrado do ponto de vista da própria produção do conhecimento pós-colonial. O que isso significa? Significa buscar orientaçôes teórico-metodológicas capazes de indicar caminhos formativos de uma nova governamentabilidade coletiva, na atualidade, particularmente das pessoas negras, em que a Europa não seja entendida mais como o "centro do mundo".

Nesse horizonte, cabem algumas questóes importantes: como situar o continente africano, no contexto dos problemas contemporâneos, tais como migraçóes, diversidades culturais, desigualdades sociais e políticas? Como pensá-lo, neste momento, quando florescem cada vez mais aspectos de barbárie civilizatória impostos pelo capitalismo neoliberal, como de justiça social e emancipação humana?

Essas questóes nos provocam a pensar a indiferença moral em relação ao destino social generalizado da população negra. Pode-se argumentar que há uma dificuldade nas pessoas em se abalar com a constatação das desigualdades raciais. Mas, para além disso, temos a tentativa de negação ou silenciamento da produção cultural e intelectual africana e afro-brasileira. Apesar disso, estamos 
gradativamente buscando superar essa condição, com o reconhecimento de intelectuais fora do eixo europeu ou norte-americano.

A partir da leitura da obra de Achille Mbembe, podemos concluir que seja necessário o reconhecimento de que o racismo se aprofunda, com base em uma relação de exploração de classe social. Com efeito, a estereotipia negativa contra o negro e o aprofundamento das diferenças entre os grupos étnicos ganham novas dimensões, com o modo de exploração capitalista. Nesse sentido, não seria exagero compreender que a obra de Mbembe pode ser considerada como espaço que impulsiona a saída daquilo que ele nomeou como "a grande noite".

SILVA, A. S.; MWEWA, C. M. Notes of a thought of circulation and crossing in Achille Mbembe. Trans/Form/Açáo, Marília, v. 45, p. 33-50, 2022. Ediçăo Especial.

\begin{abstract}
In this essay, a critical and interpretive aproach to the concept of "devir black" is nowadays brought, above all, from Cameroonian thinker Achille Mbembe. His thinking is part of a context of fluidity in the understanding of these themes based on capitalist logic in the African continent and in the world. In this way, we sought to reflect the constitution of Mbembe's thought and the way he understood the practices of governance in overcoming colonial domination. It is argued that it is necessary to claim to be black instead of denying the place attributed to it, that is, to undertake a process of denial for a "becoming". Therefore, to deny yourself as "the other" of the "other", but rather to assert yourself as your equal in difference. Indeed, the negative stereotypy against blacks and the deepening of differences between ethnic groups, takes on new dimensions, based on the mode of capitalist exploitation.
\end{abstract}

Keywords: Achille Mbembe. Circulation. Crossing. "Devir black".

\title{
REFERÊNCIAS
}

BASTIDE, Roger. Estereótipos de negros através da literatura brasileira. In: BASTIDE, Roger. Estudos afro-brasileiros. São Paulo: Perspectiva, 1973.

FANON, Frantz. Pele negra, máscaras brancas. Salvador: EDUFBA, 2008.

FANON, Frantz. Pour la Révolution Africaine. Paris: La Découverte, 2006.

MACEDO, José Rivair (org.). O pensamento africano no século XX. São Paulo: Outras Expressóes, 2016. 
MBEMBE, Achille. Afropolitanismo. Áskesis, v. 4, n. 2, p. 68-71, jul./dez. 2015.

MBEMBE, Achille. As formas africanas de autoinscrição. Estudos Afro-Asiáticos, Rio de Janeiro, a. 23, n. 1, p. 171-209, 2001.

MBEMBE, Achille. Critique de la raison nègre. Paris: La Découverte, 2013a.

MBEMBE, Achille. Sortir de la grande nuit: essai sur l'Afrique décolonisée. Paris: La Découverte, 2013 b.

MBEMBE, Achille. Sair da grande da noite: ensaio sobre a África descolonizada. Serra da Amoreira: Pedago, 2014.

MBEMBE, Achille. Crítica da razáo negra. 2. ed. Lisboa: Antígona, 2017.

MIGLIAVACCA, Adriano Moraes. Resenha: MBEMBE, Achille. Sortir de la grande nuit: essai sur l'Afrique décolonisée. Paris: La Découvert. Anos 90, Porto Alegre, v. 21, n. 40, p. 559-562, dez. 2014.

MUNANGA, Kabengele. Algumas considerações sobre "Raça, ação afirmativa e identidade negra no Brasil: fundamentos antropológicos. Revista USP, n. 68, p. 46-57, dez./fev. 2005-2006.

STEINMETZ, George. L'écriture du diable. Discours précolonial, posture ethnographique et tensions dans l'administration coloniale allemande des Samoa. Politix, v. 17, n. 66, p. 49-80, deuxième tri. 2004. doi: https://doi.org/10.3406/polix.2004.1016.

Recebido: $15 / 8 / 2020$

Aceito: 22/12/2020 